\title{
Correction to: COVID-19 and the Demand for Online Grocery Shopping: Empirical Evidence from the Netherlands
}

\section{Barbara Baarsma ${ }^{1}$. Jesse Groenewegen ${ }^{2}$}

Published online: 20 September 2021

(C) Springer Science+Business Media, LLC, part of Springer Nature 2021

\section{Correction to: De Economist https://doi.org/10.1007/s10645-021-09389-y}

In the original publication of the article, the data in Figs. 1 and 2 were published incorrectly. The corrected figures are given in below.

Additionally, in the online version there is an appendix that contains Table 3, which is not in pdf format. Rows 1 and 2 therein ("Unique visitors" and "Sales per order") should be removed. The original article has been corrected.

The original article can be found online at https://doi.org/10.1007/s10645-021-09389-y.

Barbara Baarsma

b.e.baarsma@uva.nl

Jesse Groenewegen

j.t.groenewegen@uu.nl

1 University of Amsterdam, Amsterdam, Netherlands

2 Utrecht University, Utrecht, Netherlands 


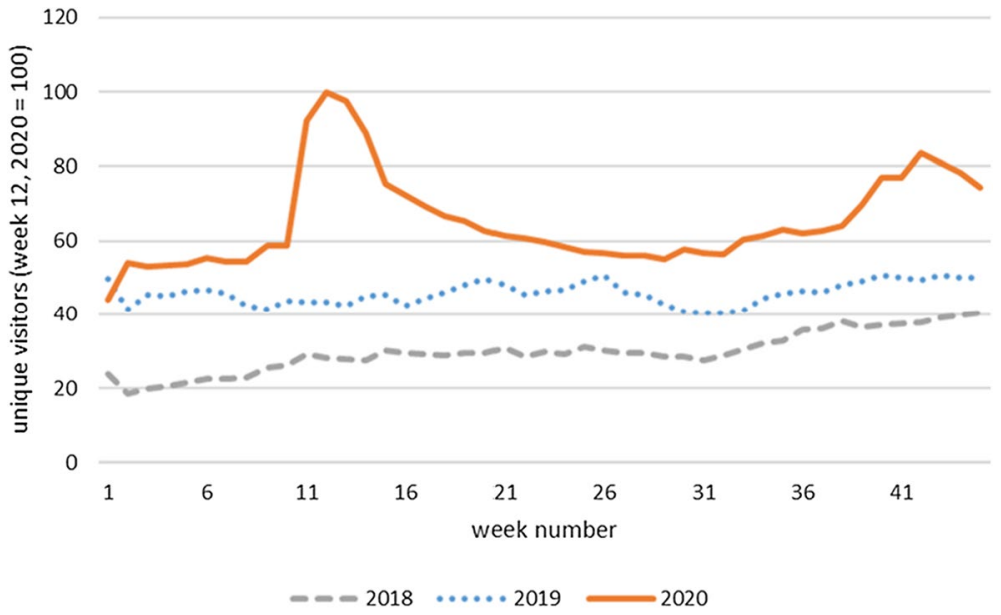

Fig. 1 Demand for online groceries, measured by number of unique visitors

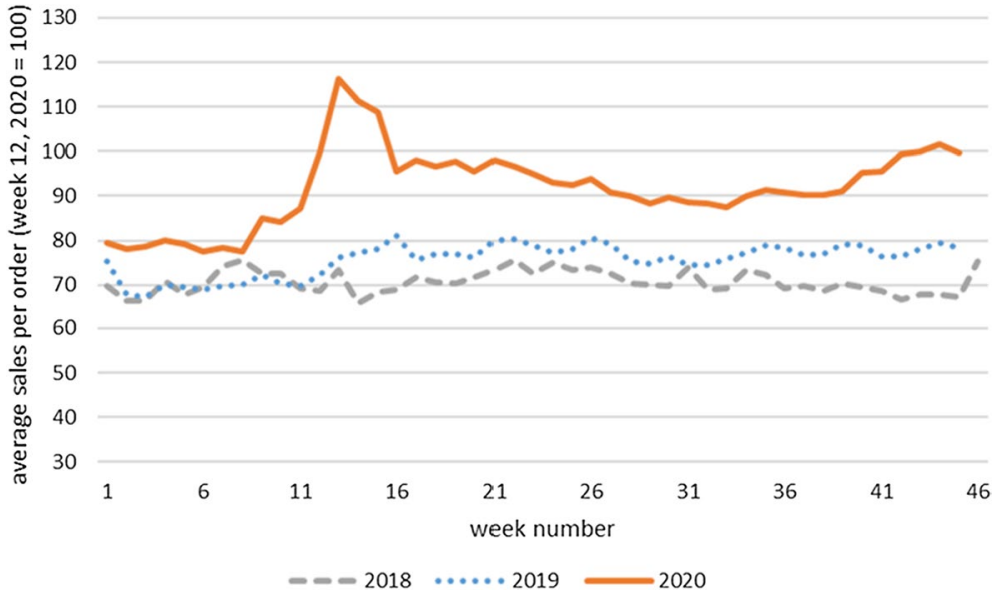

Fig. 2 Demand for online groceries, measured by average sales per order 


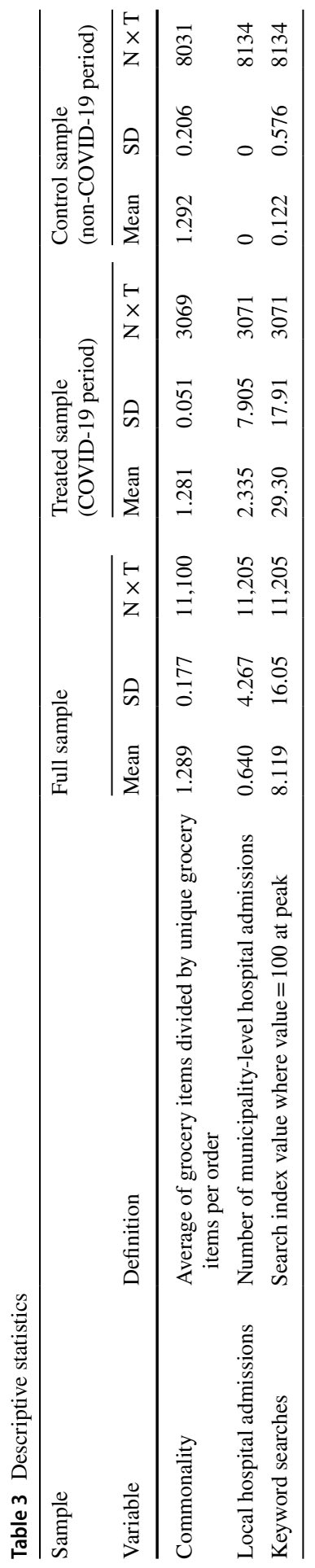


Publisher's Note Springer Nature remains neutral with regard to jurisdictional claims in published maps and institutional affiliations. 